\title{
Controllability and Stability of Hilfer Fractional Evolution Equations
}

\author{
Pallavi Bedi ${ }^{1}$, Anoop Kumar ${ }^{1}$, Thabet Abdeljawad ${ }^{2}$, and AZIZ KHAN² \\ ${ }^{1}$ Central University of Punjab \\ ${ }^{2}$ Prince Sultan University
}

November 9, 2020

\begin{abstract}
In this article, we discuss the controllability and stability of Hilfer fractional evolution equations in Banach space. We derive these results by first proving the existence and uniqueness of mild solutions for proposed system of equations. Existence and uniqueness results are obtained with the help of theory of propagation family, techniques of measure of non-compactness and fixed point theorem. An example is also given for the demonstration of obtained results.
\end{abstract}

\section{Hosted file}

mmas-2.pdf available at https://authorea.com/users/374349/articles/491885-controllabilityand-stability-of-hilfer-fractional-evolution-equations 